\title{
Examining The Relationship Between The National Survey Of Student Engagement And The ETS Business Major Field Test
}

Chris Ward, University of Findlay, USA

Dan Yates, University of Findlay, USA

Joon Young Song, University of Findlay, USA

\begin{abstract}
In this study, the authors examined the relationship between the various NSSE (National Survey of Student Engagement) survey items or classifications and the ETS Major Field Test (MFT) in Business. The sample consisted of 87 business students at a small liberal arts college. Many of the survey items were linked positively to the ETS Major Field Test. The results suggest that MFT is a better measurement than GPA for NSSE. As a noteworthy finding from the analysis, we need to mention that MFT is a better measurement of student engagement described in the NSSE rather than GPA. Therefore, it seems that the MFT is a valid external measurement of student engagement. In particular, the MFT shows a relative strength in assessing "Integration of Diversity into Coursework."
\end{abstract}

Keywords: ETS; NSSE; assessment

\section{BACKGROUND}

nstitutions of higher education are struggling to measure and report student outcomes. By around 2011, internal and external assessment outcomes are expected to be measured, reported, and available on the institution's website. This 'culture of evidence' will be expected of universities with prospective students and parents being able to view the data and potentially be able to make a more informed or uniform decision when choosing a university by comparing results between institutions for various outcomes. A variety of standardized tests such as the ETS Business Major Field Test and NSSE have been used as an external student outcome measure that may show the value of the educational experience for the student provided by the institution.

From an institutional perspective, Mirchandani et al. (2001) speculated that two simple questions needed answers "a) What do we want the students to know and/or be able to do and (b) how do we know that they know it and/can do it?" (p.51). Common outcomes that institutions want their students to know and/or be able to do include critical thinking, problem solving, written and oral communication, global awareness, ethical reasoning, and many others. Many of these outcomes are measured with rubrics developed internally by institutions and can demonstrate the student's progress at the university. Other measures of what the students know include the use of standardized tests such as the ETS Business Major Field Test and NSSE.

\section{ETS DISCUSSION}

In addition to the previously mentioned outcomes, business students are also expected to have a knowledge base in the business core including accounting, economics, management, quantitative business analysis, finance, marketing, legal and social environment, information systems and international issues. The ETS MFT in Business is an evidence based system "designed to measure a student's subject knowledge and the ability to apply facts, concepts, theories and analytical methods. Some questions are grouped in sets and based on diagrams, charts and data tables. The questions represent a wide range of difficulty and cover depth and breadth in assessing students' 
achievement levels." (http://www.ets.org/mft/about/content/bachelor_business). ETS provides each institution with a report that includes information on individual student scores along with a group mean score and percentiles. A review of the literature revealed only three studies regarding the effectiveness of the ETS MFT in Business but the articles did reveal interesting results and address some concerns we had regarding the validity of the test.

For example, Black and Duhon (2003) stated "ETS addresses content validity by using faculty committees and expert consultants to construct and evaluate the items on the business field test" (p. 93). Black \& Duhon (2003) also found men score better on the ETS MFT than women, "a business core GPA that is one point higher is associated with an ETS test score that is 7.49 points higher" (p. 94), a one-point higher composite ACT showed an increase of 1.51 points on the ETS, age plays a positive factor in ETS scores, and management majors were at a disadvantage on the ETS relative to other majors. Many of these same comparisons were made in our study. In addition, they used the results for either learning information (program and student assessment) or continuous improvement (program development and student development). Two steps they took were to suggest that underachieving students "participate in work-study programs to better integrate classroom learning and real-world applications" (p. 97) as they saw a positive association to increased ETS scores and exposure to the business environment and underachieving students could work with upperclassmen, faculty members or business leaders from the community. These are valuable insights into understanding student learning and can help guide course and curriculum revisions.

Another study done by Allen and Bycio (1997) found SAT-V (SAT - Verbal) and GPA-BUS (GPA Business) were related to MFAT-B (Major Field Achievement Test - Business). "The significantly moderately large correlation observed between the MFAT-B and GPA-BUS is a positive outcome that supports the criterionrelated validity of the test" (Allen and Bycio, 1997, p. 511-512) but they also felt "...the results would have been more positive had the MFAT-B been more strongly related to performance in the Business Core and less strongly related to, for example, SAT scores" (p. 512). This may mean that an input variable such as SAT or even good test taking skills can have a significant impact on MFAT-B scores. Regardless of this, their results do "... provide some assurance that the test functions as intended" (p. 514).

In the study by Mirchandani, Lynch and Hamilton (2001) also recognized the impact of SAT scores but found quantitative and qualitative factors to be significant. They believed that concentrating "on the material from the courses that compromised the quantitative factor (Calculus, Accounting I \& II, Finance, Operations Management, and Management Information Systems) because that factor was the most significant process variable, although the effect size was much smaller than that of the SAT" (pp. 54-55).

\section{NSSE DISCUSSION}

Many institutions in the past decade have participated in the NSSE survey to better understand how certain practices inside and outside the classroom may lead to increased student learning. According to the NSSE website, "NSSE Student engagement represents two critical features of collegiate quality. The first is the amount of time and effort students put into their studies and other educationally purposeful activities. The second is how the institution deploys its resources and organizes the curriculum and other learning opportunities to get students to participate in activities that decades of research studies show are linked to student learning" (http://nsse.iub.edu/html/about.cfm).

Pascarella, E.T., Seifert, T.A., \& Blaich, C. (2010) state "one of the major assumptions of the NSSE is that in measuring the extent to which students engage in such practices, one is indirectly measuring student cognitive and personal development during college" (p. 18). This study looked at the relationship between NSSE and other direct measures of student development and learning (effective reasoning and problem solving, moral character, inclination to inquire and lifelong learning, intercultural effectiveness, and personal well-being). A compelling finding of their study was that "Across all liberal arts outcomes, the most influential NSSE benchmark appeared to be the Enriching Educational Experiences scale, which had significant associations with three of the seven outcomes: effective reasoning and problem solving, moral character, and intercultural effectiveness" (p. 20). A 2008 research study conducted by Pascarella, et al. confirmed the "primary assumption of NSSE that in measuring student exposure to and engagement in empirically-vetted good practices, one is essentially measuring experiences that yield desired cognitive and personal development during college. Thus, collecting data on student experiences provides a window from which institutions can extrapolate to student learning" (p. 35). 
Finally, the study conducted by Gordon et al. in 2008 focused on cumulative GPA, first-year retention, job attainment upon graduation, and the decision to pursue a graduate degree as indicators of success in their student body. Two of their findings were of particular interest to us. First, they found "a stronger relationship for seniors than freshman, suggesting that engagement has an influence over the career of the student - something not readily seen after a semester and a half of experience" (p. 26). Second, one item on the NSSE provided explanatory power in retention, job attainment upon graduation and the decision to pursue further education. This item was the participation in some sort of practicum such as clinical work, co-op or internship. Our data supported this research.

Understanding the concerns regarding the ETS Business MFT and NSSE was an important aspect of moving forward with our research. As noted by Mirchandani, Lynch and Hamilton (2001), "GPA has strong internal validity and reflects student performance in the context of the curricular and pedagogical priorities at a particular institution, whereas the standardized test scores provide greater external validity and allow an institution to quickly establish a baseline and benchmark against national norms" (p. 56). We believe that both the ETS Business MFT and the NSSE have the necessary external validity for us to utilize them in further studies and possibly understand how one might even affect the other.

\section{METHODOLOGY}

In the pilot study done by Ward et al. (2009), we explored the relationship between NSSE engagement items and classifications and ETS Business MFT scores. This research is a continuation of that pilot study. At the end of the spring 2010 semester, we had a sample size of 87 students. As stated in the previous paper, the sample consists of student who completed both the ETS Business MFT and the abbreviated NSSE survey.

The response values of 16 survey items directly related to the NSSE have been standardized using the standard deviation and the mean value of each survey item. Also, the standardized scores of the survey items are grouped based on the four categories of the NSSE survey. The standardized scores of the survey items and the categories of the NSSE survey are analyzed using both the Ordinary Least Squares regression and the partial correlation coefficients.

\section{RESULTS}

The four NSSE areas we focused on for the analysis were Level of Academic and Challenge, Active and Collaborative Learning, Enriching Educational Experiences and Integration of Diversity into Coursework. As stated in our previous paper, we added or modified four questions on our NSSE survey. "We added a question regarding the types of co-curricular activities the student had done in the past year and the average number of hours worked off-campus in the 2008-2009 academic year. On the question regarding the number of hours per week the student participated in co-curricular activities, we modified the question to exclude intercollegiate sports in order to capture more volunteer activities (such as joining a club, being a resident assistant, community service, etc.). Finally, we asked the students if they had held a position of leadership on campus (Ward et al., 2009). These additions or modifications proved to be insightful.

With our current set of data, we saw positive increases in Co-curricular activity in the following areas: Community service and volunteering, community based clubs or groups, creative or performing arts, campus publication and fraternity or sorority. Our institution has focused its efforts on getting students engaged in multiple activities on campus in an effort to improve the student's experience on campus, broaden their horizons, and improve retention. The number of hours per week devoted to these activities increased as well with $18.4 \%$ of students spending 8 or more hours per week on the combined activities. A rather unsettling trend, however, is students are also spending additional hours working off campus. While the previous study showed $19.5 \%$ of 41 students worked 21 or more hours off campus, this percentage increased to $26.4 \%$ of 87 students. The economic downturn is the likely cause of this trend. Finally, holding a position of leadership on campus remained relatively stable at $34.5 \%$. This item also had a marginal correlation to MFT of .239 at the .05 level of significance. Due to our small campus, there are a significant number of opportunities for students to hold a position of leadership such as student government, resident assistant or club officer. 


\section{GPA AND MFT SHIFTS}

Several notable shifts occurred in the descriptive data and are listed in Tables 1 and 2. Table 1 shows the GPA in the bottom two and top segments remained relatively stable; there was an upward shift in from $14.6 \%$ to $23 \%$ in the 3.00-3.33 range as well as a downward shift from $41.5 \%$ to $32.2 \%$ in the $3.34-3.66$ range. Table 2 shows the overall ETS MFT scores trending upwards as the scores between 151-165 and 166-180 revealed higher percentages of students falling into those categories. In addition, the partial correlation between MFT and GPA increased from .361 to .492 supporting the work done by Carini et al. (2006) that student engagement is often positively related to GPA. These will be interesting phenomena to track as we gather more data.

Table 1. GPA

\begin{tabular}{|l|c|c|}
\hline & $\mathbf{N}=\mathbf{4 1}$ & $\mathbf{N}=\mathbf{8 7}$ \\
\hline 2.66 or lower & $2.4 \%$ & $3.4 \%$ \\
\hline 2.67 to 2.99 & $14.6 \%$ & $14.9 \%$ \\
\hline 3.00 to 3.33 & $14.6 \%$ & $23 \%$ \\
\hline 3.34 to 3.66 & $41.5 \%$ & $32.2 \%$ \\
\hline 3.67 or higher & $26.8 \%$ & $26.4 \%$ \\
\hline
\end{tabular}

The University uses a +/- grading system.

Table 2. MFT (Major Field Test Scores)

\begin{tabular}{|l|c|c|}
\hline & $\mathbf{N = 4 1}$ & $\mathbf{N}=\mathbf{8 7}$ \\
\hline 135 or lower & $4.9 \%$ & $5.7 \%$ \\
\hline 136 to 150 & $48.8 \%$ & $40.2 \%$ \\
\hline 151 to 165 & $36.6 \%$ & $39.1 \%$ \\
\hline 166 to 180 & $4.9 \%$ & $9.2 \%$ \\
\hline 181 or higher & $4.9 \%$ & $3.4 \%$ \\
\hline
\end{tabular}

\section{STUDENT ENGAGEMENT SCALES AND GPA/MFT}

As indicated in Table 3, the data continues to show that the MFT is a better measurement than GPA of student engagement as all of the scales of student engagement (Level of Academic Challenge, Active and Collaborative Learning, Enriching Educational Experiences, and Enriching Educational Experiences) were positive while the GPA relationships were predominately negative. The Integration of Diversity into Coursework scale revealed some interesting results. While the partial correlation was by far the strongest in both the MFT and GPA, it was positively related to MFT and negatively related to GPA. Additional statistical analysis supported this data as the OLS Regression data in Table 4 indicates GPA is negatively related to all of the Integration of Diversity into Coursework items. Since many of the questions in this section relate to "putting together ideas or concepts from different courses when completing assignments' or 'the extent that a project or paper required integrating ideas or information from various sources', we believe that while students may struggle with this initially, resulting in lower grades for projects or assignments in the course, the overall impact of this practice is positive. So MFT is a better and more comprehensive measurement for student engagement. For example, in a Retail Marketing class, students typically do well in the marketing section of the company research project but often struggle with the financial analysis section of the project. In addition, faculty members have more recently used the introduction, reinforce, and apply approach for concepts such as contribution margin leveraging the Bloom's Taxonomy approach to learning. It is a proven strategy that by expecting students to progress from the remembering state to the evaluating state is a proven learning approach.

Table 3. Selected Partial Correlations between GPA/MFT and Student Engagement

\begin{tabular}{|l|c|c|}
\hline & MFT & GPA \\
\hline Level of Academic Challenge & .077 & -.151 \\
\hline Active and Collaborative Learning & .064 & .042 \\
\hline Enriching Educational Experiences & .095 & -.070 \\
\hline Integration of Diversity into Coursework & $.189^{*}$ & $-.242^{* *}$ \\
\hline
\end{tabular}

$*, * *, * * *$ indicates significance at $10 \%, 5 \%$ and $1 \%$, respectively 
Table 4. OLS Regression of Integration of Diversity into Coursework Items of Student Engagement on GPA and MFT

\begin{tabular}{|c|c|c|}
\hline & MFT & GPA \\
\hline $\begin{array}{l}\text { The number of courses in the } 2009-2010 \text { academic year that expected you to put together ideas or } \\
\text { concepts from different courses when completing assignments or during class discussions }\end{array}$ & $3.489 * *$ & -.057 \\
\hline $\begin{array}{l}\text { During the 2009-2010 academic year, the extent coursework emphasized synthesizing and organizing } \\
\text { ideas, information, or experiences into new, more complex interpretations and relationships }\end{array}$ & -.900 & -.106 \\
\hline $\begin{array}{l}\text { During the } 2009-2010 \text { academic year, the extent that a paper or project that required integrating ideas } \\
\text { or information from various sources. }\end{array}$ & 1.646 & -.016 \\
\hline
\end{tabular}

$*, * *, * * *$ indicates significance at $10 \%, 5 \%$ and $1 \%$, respectively

\section{STUDENT ENGAGEMENT ITEMS AND GPA/MFT}

Partial correlations further explored the specific items of engagement associated with internal assessment (GPA) and external assessment (MFT). Table 5 reports only those partial correlations that achieved statistical significance in either GPA or MFT. Noted again was the trend for GPA to be overall negatively correlated to the survey item while MFT was positive in two of the three items. As stated earlier, more students are involved in and spend more time doing co-curricular activities. This appears to have an overall negative impact on GPA but a positive impact on MFT. Students may be spending more time on these activities and neglecting their day to day work in class but since the ETS Business MFT is a one time test that requires very little study time, they perform at an acceptable level. The partial correlations of 'the number of courses in the 2009-2010 academic year that expected you to put together ideas or concepts from different courses when completing assignments or during class discussions' mirrored the OLS regression data as the MFT showed a significant positive correlation to MFT while the correlation to GPA, while not significant, was negative.

Table 5. Partial Correlations between Survey Items and MFT and GPA

\begin{tabular}{|c|c|c|}
\hline & MFT & GPA \\
\hline Co-curricular activities you have done in the past year. (check all that apply) & .126 & $-.319 * * *$ \\
\hline $\begin{array}{l}\text { The number of courses in the } 2009-2010 \text { academic year that expected you to put together ideas } \\
\text { or concepts from different courses when completing assignments or during class discussions }\end{array}$ & $.268 * *$ & -.162 \\
\hline $\begin{array}{l}\text { During the 2009-2010 academic year, the extent coursework emphasized synthesizing and } \\
\text { organizing ideas, information, or experiences into new, more complex interpretations and } \\
\text { relationships. }\end{array}$ & -.069 & $-.283 * *$ \\
\hline
\end{tabular}

$*, * *, * * *$ indicates significance at $10 \%, 5 \%$ and $1 \%$, respectively

Finally, gender and rank continue to be significant. The OLS Regression showed males score higher on the MFT test than females (-5.754 at the .05 level of significance); however, females tend to have a higher GPA. Mirchandani et al. (2001) showed similar results in their study stating "It has been shown that certain subgroups within the population, most notably women and minorities, perform less well on standardized tests in general than do White males..." (p. 52). Females may be better organized and detail oriented with those traits lending themselves to potentially better quality assignments and projects, and consequently higher GPAs. As you would expect, seniors scored higher than juniors signifying a maturation and integration of knowledge from their junior to their senior year.

\section{DISCUSSION}

The results of this study are similar to what other researchers have found regarding engagement but we took the analysis one step further. By adding the ETS MFT to the study, we are able to link student engagement to a desirable business learning outcome (content knowledge in the ETS MFT). The level of significance and small sample size are still of some concern but the trends in the data are encouraging. Additional schools have shown interest in being a part of our study and we hope to incorporate them during the next academic year.

The trends in the data did indicate potential steps that institutions could take to increase their ETS MFT scores. By linking two externally valid tests, the ETS MFT and NSSE, an institution's first step could be to 
encourage specific behaviors in the NSSE that related to higher ETS MFT scores. For example, integrating diversity into coursework, specifically, putting together ideas or concepts from different courses when completing assignments or during class discussions showed the highest positive partial correlation between a NSSE item and the ETS MFT. The second step could be to encourage students to participate in enriching educational experiences such as co-curricular activities, internships, study abroad and holding a position of leadership on campus. On our campus, we have over 60 clubs as well as a variety of sororities and fraternities. This participation not only provides the students with a social activity but an intellectual one as well. Students in the marketing club often develop marketing plans for small business owners. Often included in these plans are cost analyses for various media, budgets and return on investment measures. This blends the marketing and finance disciplines that will likely be expected of them in a job. We have also witnessed a considerable amount of mentoring in these activities as well as increased in-class participation from those students who are active in co-curricular activities.

There is one note of caution though; Gordon et al. (2008) found "that Enriching Educational Experiences have a significant and negative effect on freshman GPA (but no effect on senior GPA)" (p. 26). They believed, and we agree, that a plausible explanation could be that too positive an engaging experience detracts from spending time on their studies.

While institutions continue to develop internal and external validation of learning outcomes, our study could be useful in determining the type of instrument the institution desires to use as well as where they allocate institutional resources regarding assessment. The NSSE and the ETS MFT, at least for business, appear to be two very useful tools in understanding and communicating learning outcomes.

As a noteworthy finding from the analysis, we need to mention that MFT is a better measurement of student engagement described in the NSSE rather than GPA. Therefore, it seems that the MFT is a valid external measurement of student engagement. In particular, the MFT shows a relative strength in assessing "Integration of Diversity into Coursework."

\section{AUTHOR INFORMATION}

Dr. Ward is an Associate Professor of Business with The University of Findlay. Professor Ward brings her expertise from two Fortune 500 companies into the classroom teaching operations and logistics, marketing, management, strategy and policy, communications, and research. Professor Ward holds the following degrees: University of Sarasota, EdD, Organizational Leadership; The University of Findlay, MBA and The University of Findlay, Bachelor of Science in Business Administration. She is also a Six Sigma Black Belt, a 2008 Ohio Partnership for Excellence Examiner, and completed the NxLevel Certification Course for Instructor Certification for teaching business plans. Her areas of research include student engagement, active learning, assessment and promotion and tenure.

Dan Yates is an assistant professor of business at The University of Findlay. His teaching interests include entrepreneurship, leadership, organization development, and business strategy. Yates holds a $\mathrm{PhD}$ degree in Management from Northcentral University. He also has a MBA from University of Dayton, a Master of Organization Development degree from Bowling Green State University, and a BS in Accounting from Tiffin University. He completed the NxLevel Certification Course for Instructor Certification for teaching business plans at the Innovation Center (Ohio University). He has 30 years industrial and governmental experience.

Dr. Song is an assistant professor of Finance at the University of Findlay. Prior to joining the University of Findlay, Dr. Song has worked for a nation-wide business newspaper and a researcher at the LG Economic Research Institute in Korea. Professor Song earned a doctoral degree in business administration with concentration of finance from University of Tennessee (Knoxville). He also holds several master degrees in business administration and economics from Seoul National University, Syracuse University, and the University of Tennessee. His current research interests are in the areas of Asset Pricing, Behavioral Finance, and Corporate Governance. 


\section{REFERENCES}

1. Allen, J. S., Bycio, P. (1997). An Evaluation of the Educational Testing Service Major Field Achievement Test in Business. Journal of Accounting Education, 15(4), 503-514.

2. Andrews, C.P. (Sept/Oct 2007). Service Learning: Applications and Research in Business. Journal of Education for Business, 19-26.

3. Black, T.H., \& Duhon, D.L. (Nov/Dec 2003). Evaluating and Improving Student Achievement in Business Programs: The Effective Use of Standardized Assessment Tests. Journal Education for Business, 90-98.

4. Carini, R. M., Kuh, G. D. \& Klein, S. P. (2006). Student engagement and student learning: Testing the linkages. Research in Higher Education Vol. 47 1, 1-32.

5. Gordon, J., Ludlum, J., \& Hoey, J. J. (2008). Validating NSSE Against Student Outcomes: Are They Related. Res Higher Education, 49, 19-39.

6. Kazin, C. \& Payne, D.G. (March/April 2009). Ensuring Educational Quality Means Assessing. Retrieved on July 6, 2010 from http://www.ets.org/education topics/learning_outcomes.

7. Kuh, G. D., Cruce, T.M., Shoup R., Kinzie, J., \& Gonyea, R.M. (September/October 2008). Un masking the Effects of Student Engagement on First-Year College Grades and Persistence. The Journal of Higher Education, 79(5), 540-563.

8. Mirchandani, D., Lynch, R., \& Hamilton, D. (Sept/Oct 2001). Using the ETS Major Field Test in Business: Implications for Assessment. Journal of Education for Business, 51-98.

9. National Survey of Student Engagement. Retrieved July 6, 2010 from http://nsse.iub.edu/.

10. Pascarella, E.T., Seifert, T.A., \& Blaich, C. (2008, November). Validation of the NSSE benchmarks and deep approaches to learning against liberal arts outcomes. Paper presented at the annual meeting of the Association for the Study of Higher Education. Jacksonville, FL. Available from: http://www.education.uiowa.edu/crue/publications/index.htm.

11. Pascarella, E.T., Seifert, T.A., \& Blaich, C. (January and February 2010). How Effective are the NSSE Benchmarks in Predicting Important Educational Outcomes. Change, 42(1), 16-22.

12. Ward, C., Yates, D., \& Song, J. (2009). Exploring the relationship between student engagement and common business knowledge: A pilot study. American Journal of Business Education, (2) 9. 
NOTES 